\title{
Выращивание, структура и температурная зависимость ширины запрещенной зоны монокристаллов $\mathrm{Cu}_{2} \mathrm{ZnGeS}_{4}$
}

\author{
(C) И.В. Боднарь ${ }^{1}$, В.А. Ящук ${ }^{1}$, В.Н. Павловский ${ }^{2}$, Г.П. Яблонский ${ }^{2}$ \\ ${ }^{1}$ Белорусский государственный университет информатики и радиоэлектроники, \\ 220013 Минск, Беларусь \\ ${ }^{2}$ Институт фризики Национальной академии наук Беларуси, \\ 220072 Минск, Беларусь \\ E-mail: chemzav@bsuir.by
}

Поступила в Редакцию 29 декабря 2021 г.

В окончательной редакции 19 января 2022 г.

Принята к публикации 19 января 2022 г.

\begin{abstract}
Методом химических газотранспортных реакций выращены монокристаллы соединения $\mathrm{Cu}_{2} \mathrm{ZnGeS}_{4}$. Oпределен их состав и кристаллическая структура. Показано, что выращенные монокристаллы кристаллизуются в тетрагональной структуре. По спектрам пропускания в области края собственного поглощения в интервале температур 10-320 K определена ширина запрещенной зоны указанных монокристаллов. Установлено, что ширина запрещенной зоны с понижением температуры возрастает.
\end{abstract}

Ключевые слова: монокристаллы, кристаллическая структура, спектры пропускания, ширина запрещенной зоны.

DOI: 10.21883/FTP.2022.05.52353.9801

\section{1. Введение}

В последнее время все большую актуальность приобретает вопрос о создании новых эффективных полупроводниковых материалов, на основе которых могут быть созданы полупроводниковые приборы с новыми функциональными возможностями. К таким материалам относятся четверные соединения с общей формулой $\mathrm{Cu}_{2} \mathrm{~A}^{\mathrm{II}} \mathrm{B}^{\mathrm{IV}} \mathrm{X}_{4}^{\mathrm{VI}}$, где $\mathrm{A}^{\mathrm{II}}=\mathrm{Zn}, \mathrm{Cd} ; \mathrm{B}^{\mathrm{IV}}=\mathrm{Si}, \mathrm{Ge}, \mathrm{Sn}$ и $\mathrm{X}^{\mathrm{VI}}=\mathrm{S}, \mathrm{Se}, \mathrm{Te}$, которые образуют большой класс структурно родственных соединений. Указанные материалы имеют прямую запрещенную зону, большой коэффициент оптического поглощения $\left(\sim 10^{4} \mathrm{~cm}^{-1}\right)$ и ширину запрещенной зоны от 1.0 до 2.5 эВ. Это делает указанные материалы кандидатами для создания на их основе солнечных элементов с высоким кпд [1-5].

К таким материалам относится и соединение $\mathrm{Cu}_{2} \mathrm{ZnGeS}_{4}$. В литературе имеются ограниченные сведения о выращивании монокристаллов этого соединения, а имеющиеся данные о физико-химических свойствах противоречивы, что связано, вероятнее всего, с различными методами выращивания и характером плавления этого соединения [6-8].

В настоящей работе представлены данные о выращивании монокристаллов $\mathrm{Cu}_{2} \mathrm{ZnGeS}_{4}$ методом химических газотранспортных реакций, определении их состава, кристаллической структуре, спектрах пропускания и изменении ширины запрещенной зоны в интервале температур 10-300 K.

\section{2. Методика эксперимента}

Монокристаллы $\mathrm{Cu}_{2} \mathrm{ZnGeS}_{4}$ выращивали методом химических газотранспортных реакций с использованием иода в качестве переносчика. Для выращивания указанных монокристаллов использовали поликристаллические слитки, полученные направленной кристаллизацией расплава в вертикальной однозонной печи. Исходными материалами служили медь, цинк, германий и сера чистотой $>99.999 \%$. Элементарные компоненты, взятые в соотношениях $\mathrm{Cu}_{2} \mathrm{ZnGeS}_{4}=2: 1: 1: 4$ в количестве $\sim 15-20$ г, загружали в двойные кварцевые ампулы с оттянутым в виде конуса дном. Перед загрузкой компонентов ампулы проходили химико-термическую обработку.

После вакуумирования ампулы до остаточного давления $\sim 10^{-3}$ Па ее помещали во вторую кварцевую ампулу большего диаметра, которую также вакуумировали. К наружной ампуле снизу приваривали кварцевый стержень, служивший держателем, который присоединяли к вибратору. В процессе нагревания ампул в печи применяли вибрационное перемешивание, которое в значительной мере ускоряет образование соединения и препятствует нарушению целостности ампул.

В начальный период температуру в печи повышали со скоростью $\sim 50 \mathrm{~K} /$ ч до $\sim 720 \mathrm{~K}$. При указанной температуре проводилась изотермическая выдержка в течение $\sim 2-3$ ч с включением вибрации. Это необходимо для того, чтобы такое легколетучее вещество как сера при этой температуре, когда давление его пара не превышает $10^{5}$ Па, успело частично или полностью прореагировать с медью, цинком и германием. Затем с такой же скоростью температуру повышали до $\sim 1400 \mathrm{~K}$ (без выключения вибрационного перемешивания) и снова выдерживали 2 ч. После этого вибрацию отключали и проводили направленную кристаллизацию расплава, понижая температуру печи со скоростью $\sim 2 \mathrm{~K} /$ ч до $\sim 1080 \mathrm{~K}$, и при этой температуре проводили отжиг полученных слитков в течение 300 ч. 


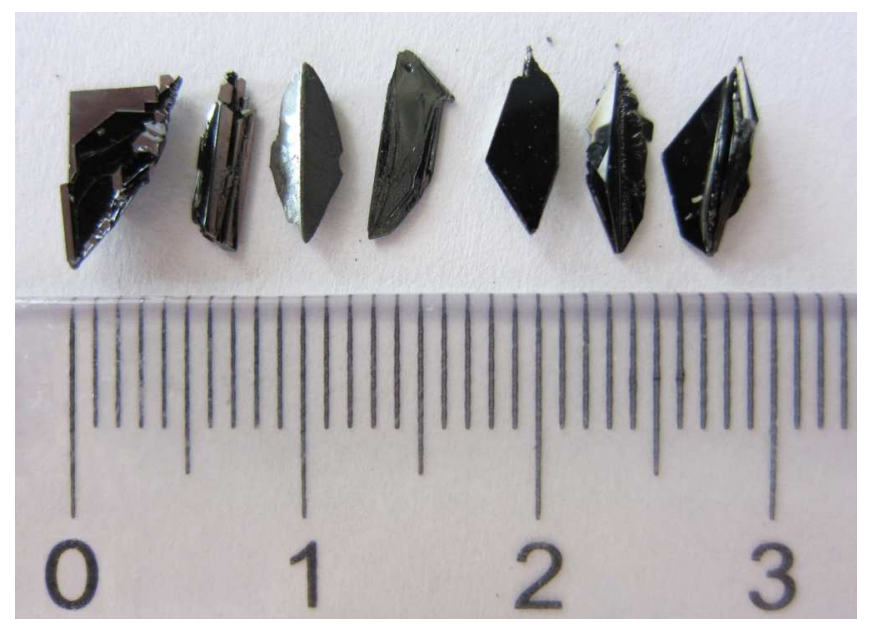

Рис. 1. Фотография монокристаллов соединения $\mathrm{Cu}_{2} \mathrm{ZnGeS}_{4}$.

Полученные поликристаллические слитки измельчали в порошок и использовали для выращивания монокристаллов. Процессы переноса исходных материалов и рост монокристаллов проводили в кварцевых ампулах с внутренним диаметром $\sim 20$ мм и длиной $\sim 180$ мм. Первоначально ампула состояла из двух секций. В одну из них загружали соединение $\mathrm{Cu}_{2} \mathrm{ZnGeS}_{4}$ в виде порошка в количестве $3-5$ г, в другую - капилляр с иодом, предварительно откачанный и запаянный. Концентрация переносчика составляла $\sim 5 \mathrm{Mr} / \mathrm{cm}^{3}$. Ампулу вакуумировали, а затем с помощью „магнитного“ молотка вскрывали капилляр с иодом, который перегоняли в секцию, где находился порошок соединения. Подготовленную ампулу размещали в горизонтальной двухзонной печи. Нагрев вели таким образом, чтобы температура зоны реакции, где находился порошок соединения, была на $\sim 100 \mathrm{~K}$ ниже, чем температура зоны кристаллизации. Это необходимо для протекания реакции между кристаллами и иодом с образованием иодидов металлов и для очистки зоны кристаллизации от возможных неконтролируемых центров кристаллизации. Через определенное время температуру в зонах выравнивали и устанавливали $970 \mathrm{~K}$, а затем повышали температуру в зоне реакции до создания градиента температур между зонами $\sim 80 \mathrm{~K}$.

Вид выращенных в таких условиях пластинчатых монокристаллов представлен на рис. 1. Состав выращенных кристаллов определяли с помощью микрозондового рентгеноспектрального анализа на установке „Сатеса-MBX 100“. Относительная погрешность определения компонентов составляла $\pm 5 \%$. Структуру и параметры элементарной ячейки кристаллов устанавливали рентгеновским методом. Угловые положения линий дифракционного спектра записывали на рентгеновском аппарате ДРОН $3 \mathrm{M} \mathrm{в} \mathrm{Cu} K_{\alpha}$-излучении с графитовым монохроматором.
Спектры пропускания в области температур $T=10-320 \mathrm{~K}$ регистрировали на установке, состоящей из гелиевого рефрижератора замкнутого цикла, монохроматора, кремниевой ПЗС-линейки, галогеновой лампы в качестве источника излучения и персонального компьютера. Для проведения измерений выращенные монокристаллы шлифовали и полировали с одной стороны (другая сторона была зеркально гладкая). Для снятия нарушенного слоя, образовавшегося при механической обработке монокристаллов, непосредственно перед измерениями спектров образцы подвергали обработке в химическом травителе состава $-\mathrm{Br}_{2}: \mathrm{C}_{2} \mathrm{H}_{5} \mathrm{OH}=1: 3$. Толщина образцов составляла $\sim 20$ мкм.

\section{3. Результаты и обсуждение}

Данные микрозондовых рентгеноспектральных измерений показали, что содержание элементов в выращенных монокристаллах составляет $\mathrm{Cu}: \mathrm{Zn}: \mathrm{Ge}: \mathrm{S}=$ $=25.66: 12.14: 12.95: 49.25$, что удовлетворительно согласуется с заданным составом в исходной шихте $\mathrm{Cu}: \mathrm{Zn}: \mathrm{Ge}: \mathrm{S}=25.00: 12.50: 12.50: 50.00$.

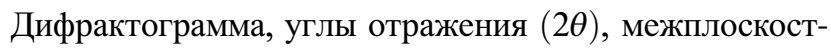
ные расстояния $(d)$, относительные интенсивности рефлексов $\left(I / I_{0}\right)$, индексы Миллера $(h k l)$ для монокристаллов $\mathrm{Cu}_{2} \mathrm{ZnGeS}_{4}$ представлены на рис. 2 и в таблице.

Результаты рентгеновских исследований показали, что на всех записанных дифрактограммах присутствуют максимумы отражения, характерные для тетрагональной структуры (кестерит). По измеренным значениям углов дифракции были рассчитаны межплоскостные расстояния для различных плоскостей отражения, по которым методом наименьших квадратов определяли параметры элементарной ячейки. Для исследуемого соединения $\mathrm{Cu}_{2} \mathrm{ZnGeS}_{4}$ они равны: $a=5.342 \pm 0.005 \AA$, $c=10.51 \pm 0.01 \AA$.

На рис. 3 представлены спектры пропускания указанных монокристаллов в области края поглощения в интервале температур $T=10-320 \mathrm{~K}$. Видно, что с

Результаты рентгеновского анализа кристаллов $\mathrm{Cu}_{2} \mathrm{ZnGeS}_{4}$

\begin{tabular}{c|l|l|l|l|c}
\hline \multicolumn{2}{c|}{ Эксперимент } & \multicolumn{2}{|c|}{ Расчет } & \multirow{2}{*}{$h k l$} & \multirow{2}{*}{$I / I_{0}$} \\
\cline { 1 - 4 } $2 \theta$, град & $d, \AA$ & $2 \theta$, град & $d, \AA$ & & \\
\hline 29.09 & 3.07 & 29.14 & 3.06 & 112 & 100 \\
33.53 & 2.6703 & 33.57 & 2.6671 & 200 & 10 \\
34.07 & 2.6293 & 34.02 & 2.6329 & 004 & 12 \\
48.25 & 1.8844 & 48.26 & 1.8842 & 220 & 7 \\
48.57 & 1.8727 & 48.59 & 1.8721 & 204 & 18 \\
57.24 & 1.6080 & 57.26 & 1.6076 & 312 & 14 \\
57.99 & 1.5890 & 58.00 & 1.5888 & 116 & 3.6 \\
60.31 & 1.5333 & 60.34 & 1.5327 & 224 & 6 \\
77.98 & 1.2242 & 77.98 & 1.2242 & 332 & 3.5 \\
78.69 & 1.2149 & 78.68 & 1.2151 & 413 & 4.1 \\
90.24 & 1.0870 & 90.25 & 1.0869 & 424 & 60
\end{tabular}




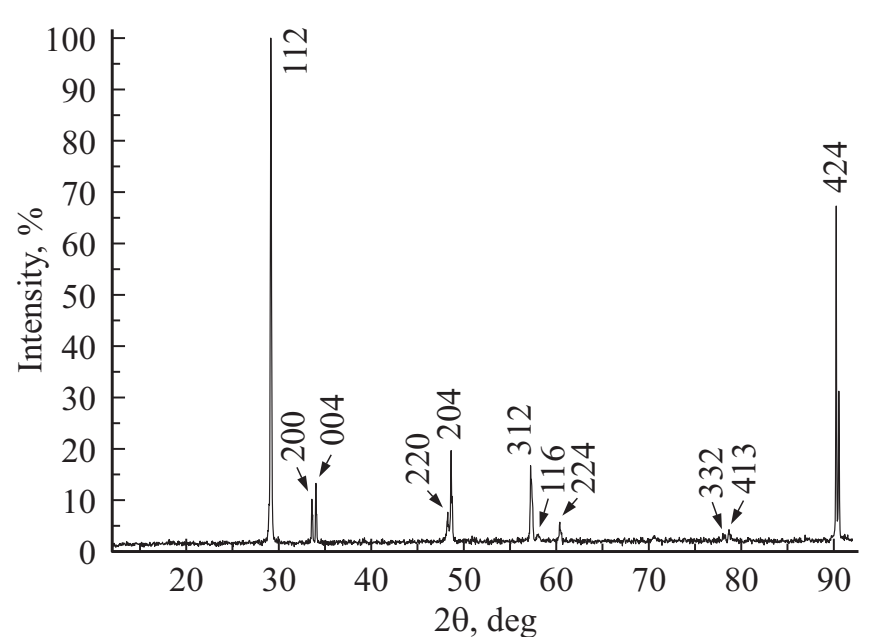

Рис. 2. Дифрактограмма кристаллов $\mathrm{Cu}_{2} \mathrm{ZnGeS}_{4}$.

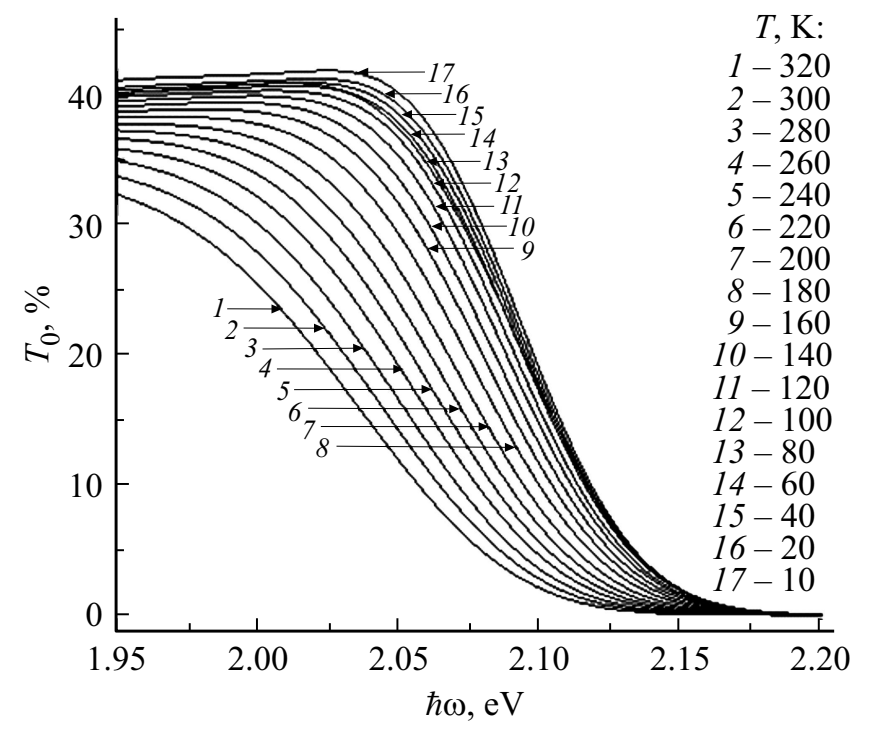

Рис. 3. Спектры пропускания монокристаллов $\mathrm{Cu}_{2} \mathrm{ZnGeS}_{4}$.

понижением температуры спектры смещаются в коротковолновую область.

По измеренным спектрам пропускания $T_{\text {opt }}$ рассчитывали коэффициент поглощения $\alpha$ по формуле (1), учитывающей многократное внутреннее отражение в плоскопараллельном образце [9-11]:

$$
\alpha=\frac{1}{d} \ln \left\{\frac{(1-R)^{2}}{2 T_{\mathrm{opt}}}+\sqrt{\left[\frac{(1-R)^{2}}{2 T_{\mathrm{opt}}}\right]^{2}+R^{2}}\right\},
$$

где $d-$ толщина образца, $T_{\text {opt }}-$ коэффициент пропускания, $R$ - коэффициент отражения.

Известно, что соединения $\mathrm{Cu}_{2} \mathrm{~A}^{\mathrm{II}} \mathrm{B}^{\mathrm{IV}} \mathrm{X}_{4}^{\mathrm{VI}}$, к которым относится и соединение $\mathrm{Cu}_{2} \mathrm{ZnGeS}_{4}$, являются материалами с прямой запрещенной зоной, поэтому спектральная зависимость коэффициента поглощения запишется в следующем виде:

$$
\alpha=A \frac{\left(\hbar \omega-E_{g}\right)^{1 / 2}}{\hbar \omega},
$$

где $A$ - константа, $E_{g}$ - ширина запрещенной зоны.

Спектральные зависимости $(\alpha \hbar \omega)^{2}$ от энергии фотона $(\hbar \omega)$ для монокристаллов $\mathrm{Cu}_{2} \mathrm{ZnGeS}_{4}$ представлены на рис. 4. Видно, что указанные зависимости имеют ярко выраженные линейные участки, что свидетельствует (как и рентгеновские данные) о равновесности и однородности выращенных монокристаллов. Ширину запрещенной зоны определяли экстраполяцией прямолинейных участков зависимости $(\alpha \hbar \omega)^{2}$ от $(\hbar \omega)$ до пересечения с осью абсцисс. Полученные нами значения ширины запрещенной зоны для монокристаллов равны: $2.068,2.112$ и 2.113 эВ при 300,80 и $10 \mathrm{~K}$ соответственно.

На рис. 5 представлена температурная зависимость ширины запрещенной зоны $E_{g}(T)$ монокристаллов $\mathrm{Cu}_{2} \mathrm{ZnGeS}_{4}$, полученная на основе экспериментальных данных по измерениям коэффициента пропускания в интервале температур $10-320 \mathrm{~K}$ (точки). Видно, что указанная зависимость имеет вид, характерный для большинства полупроводниковых материалов, с понижением температуры $E_{g}$ возрастает [10-13].

Для описания температурной зависимость ширины запрещенной зоны было использовано следующее выражение [14]:

$$
E_{g}(T)=E_{G}(0)-\frac{\chi \cdot \Theta}{2}\left(\sqrt[4]{1+\frac{\pi^{2}}{6}\left(\frac{2 T}{\Theta}\right)^{2}+\left(\frac{2 T}{\Theta}\right)^{4}}-1\right)
$$

где $E_{g}(0)$ - ширина запрещенной зоны при $T=0 \mathrm{~K}$; $\chi$ - параметр, определяющий тангенс угла наклона

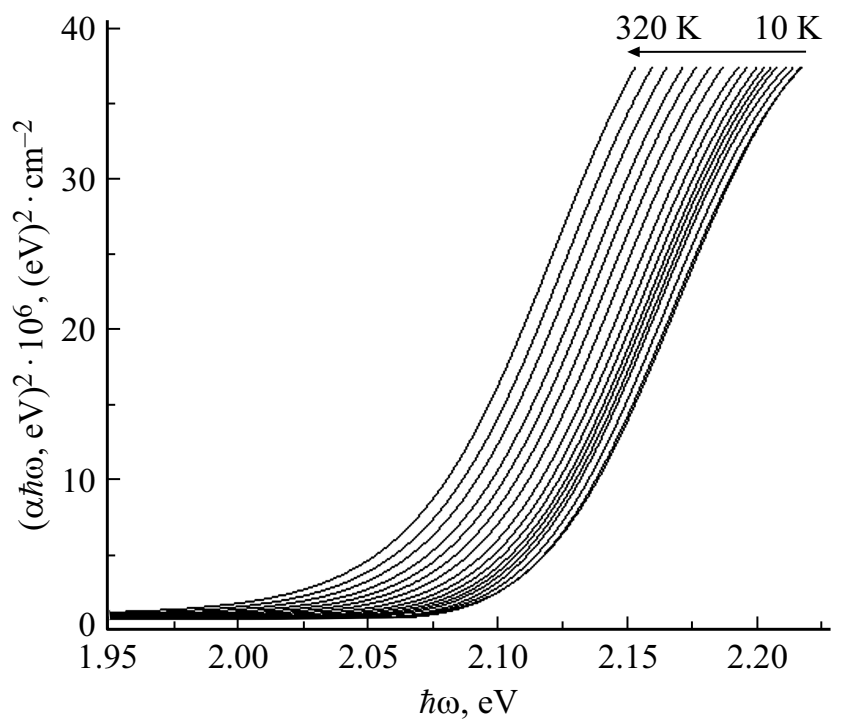

Рис. 4. Спектральные зависимости $(\alpha \hbar \omega)^{2}$ от энергии фотона монокристаллов $\mathrm{Cu}_{2} \mathrm{ZnGeS}_{4}$. 


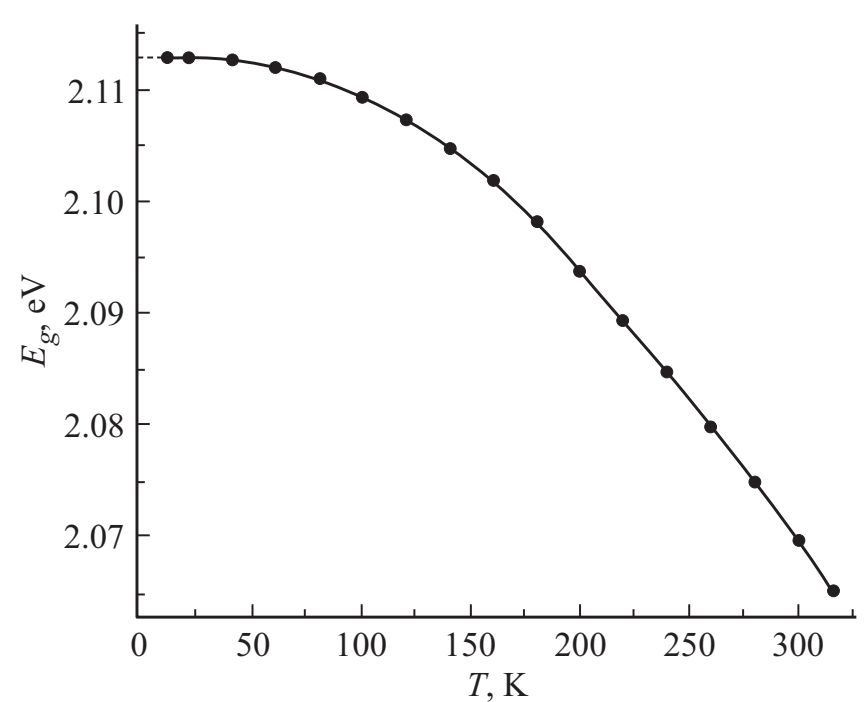

Рис. 5. Температурная зависимость ширины запрещенной зоны $E_{g}(T)$ монокристаллов $\mathrm{Cu}_{2} \mathrm{ZnGeS}_{4}$.

касательной к кривой $E_{g}(T) \quad\left(\chi=-d E(T) /\left.d T\right|_{T \rightarrow \infty}\right)$; $\theta$ - эффективная фононная температура, связанная с температурой Дебая $\theta_{\mathrm{D}}$ выражением $\theta=(3 / 4) \theta_{\mathrm{D}}$.

Величину $\chi$ определяли путем нахождения зависимости, наилучшим образом удовлетворяющей экспериментальным данным $E_{g}(T)$ в интервале температур $10-320 \mathrm{~K}$. Расчетная зависимость $E_{g}(T)$ по соотношению (3) представлена на рис. 5 в виде сплошной линии. Видно, что расчетные величины хорошо согласуются с экспериментальными результатами.

\section{4. Заключение}

Методом химических газотранспортных реакций выращены пластинчатые монокристаллы соединения $\mathrm{Cu}_{2} \mathrm{ZnGeS}_{4}$. Определен состав полученных монокристаллов и их структура. Показано, что соединение $\mathrm{Cu}_{2} \mathrm{ZnGeS}_{4}$ кристаллизуется в тетрагональной структуре с параметрами $a=5.342 \pm 0.005 \AA, c=10.51 \pm 0.01 \AA$.

По спектрам пропускания в интервале температур $10-320 \mathrm{~K}$ определена ширина запрещенной зоны монокристаллов и построена ее температурная зависимость. Установлено, что ширина запрещенной с понижением температуры возрастает от 2.064 эВ при $T=320 \mathrm{~K}$ до 2.113 эВ при $T=10 \mathrm{~K}$.

\section{Финансирование работы}

Работа выполнена в рамках European Project INFINITE-CELL (Ref. No. H2020-MSCA-RISE-2017777968, 2017-2021).

\section{Конфликт интересов}

Авторы заявляют, что у них нет конфликта интересов.

\section{Список литературы}

[1] W. Wang, M.T. Winkler, O. Gunawan, T. Gokmen, T.K. Todorov, Yu. Zhu, D.B. Mitzi. Adv. Energy Mater., 4, 201301465 (2014). DOI: 10.1002/aenm

[2] T.K. Todorov, J. Tang, S. Bag, O. Gunawan, T. Gokmen, Yu. Zhu, D.B. Mitzi. Adv. Energ. Mater., 3, 34 (2013).

[3] I. Repins, C. Beall, N. Vora, C. De. Hart, D. Kuciauskas, P. Dippo, B. To, J. Mann, W.C. Hsu, A. Goodrich, R. Noufi. Sol. Energy Mater. Solar Cells, 101, 154 (2012).

[4] G.M. Ford, Q. Guo, R. Agrawal, H.W. Hillhouse. Chem. Mater., 23, 2626 (2011).

[5] Choong-Il Lee, Chang-Dae Kim. J. Korean Phys. Soc., 37, 364 (2000).

[6] K. Ito, T. Nakazawa. Jpn. J. Appl. Phys., 27, 2094 (1988).

[7] N. Nakayama, K. Ito. Appl. Surf. Sci., 92, 171 (1996).

[8] O.V. Parasyuk, L.D. Gulay, Ya.E. Romanyuk, L.V. Piskach. J. Alloys Compd., 329, 202 (2001).

[9] Ю.И. Уханов. Оптические свойства полупроводников (М., Наука, 1977).

[10] С.И. Рембеза. Методы измерения основных параметров полупроводников (Воронеж, ВГУ, 1989).

[11] Р. Уиллардсон. Оптические свойства полупроводников (М., Мир, 1970).

[12] I.V. Bodnar, I.A. Victorov, V.M. Dabranski, M.A. Osipova. Phys. Status Solidi C, 6, 1130 (2009).

[13] И.В. Боднарь, Чан Бинь Тхан. Докл. БГУИР, 1, 57 (2018).

[14] R. Pässler. Phys. Status Solidi B, 200, 155 (1997).

Редактор Г.А. Оганесян

\section{Growth, crystal structure and temperature dependence of the band gap of $\mathrm{Cu}_{2} \mathrm{ZnGeS}_{4}$ single crystals}

\author{
I.V. Bodnar ${ }^{1}$, V.A. Yashchuk ${ }^{1}$, V.N. Pavlovskii ${ }^{2}$, \\ G.P. Yablonskii ${ }^{2}$ \\ ${ }^{1}$ Belarusian State University \\ of Informatics and Radioelectronics, \\ 220013 Minsk, Belarus \\ ${ }^{2}$ Institute of Physics of the National Academy \\ of Sciences of Belarus, \\ 220072 Minsk, Belarus
}

Abstract $\mathrm{Cu}_{2} \mathrm{ZnGeS}_{4}$ single crystals were grown by chemical vapor transport reaction method. Their composition and crystal structure were determined. It was shown that the obtained single crystals crystallize in a tetragonal structure. The band gap of the obtained single crystals was determined basing on transmission spectrum in the region of the absorption edge in temperature range of $10-320 \mathrm{~K}$. It was found that band gap width increases with decreasing of temperature. 